\title{
O Império das Emoções e a Literatura Sentimental no Brasil
}

\author{
Roberta Manuela de Barros de Andrade ${ }^{1}$ \\ Erotilde Honório ${ }^{2}$
}

\begin{abstract}
Resumo: Os bens culturais massivos estão, historicamente, centrados na construção de certa cultura dos sentimentos, enaltecida e exacerbada. Esta retórica do excesso encontra um lugar privilegiado na literatura de massa. Neste contexto, este trabalho objetiva realizar uma reflexão sobre as interrelações entre literatura sentimental e extravagância emotiva, a partir da obra de Elinor Glyn, popular autora inglesa, cujos livros foram publicados, no Brasil, entre os anos 1930 e os anos 1960, pela Coleção Biblioteca das Moças. Assim, esta pesquisa se propõe a realizar uma análise estrutural e argumentativa das obras de Elinor Glyn, enfocando como as concepções de amor, paixão e erotismo ali concebidas obedecem a certa lógica melodramática, responsável, em parte, por torná-la um grande sucesso editorial no período em destaque.
\end{abstract}

Palavras- chave: Literatura sentimental. Retórica do excesso. Imaginação melodramática.

Abstract: Cultural massive goods are, historically, focused on the construction of a certain culture of feelings, exalted and exaggerated. This excess rhetoric has a privileged place in the literature of mass. In this context, this work aims at reflecting on the interrelations between sentimental literature and emotional extravagance, from the work of Elinor Glyn, a popular English author, whose books were published in Brazil, between the 1930s and 1960s, by the Collection Library of Young Women. Thus, this research intends to perform a structural argumentative analysis of the works of Elinor Glyn, focusing on how the concepts of love, passion and eroticism which were born there obey a certain melodramatic logic, responsible, in part, for making it a great publishing success of this period of time.

Key-words: Sentimental literature. Excess rhetoric. Melodramatic imagination.

\section{A Retórica do Excesso e a Literatura Sentimental}

Senhores, agrada-vos ouvir uma bela história de amor e morte? Assim, inicia-se a saga de Tristão e Isolda, narrativa celta do século XII, que conta as desventuras de dois jovens que se amam e acabam, ao sucumbirem a uma paixão impossível, morrendo. Com certeza, até hoje, nada no mundo nos agradaria mais ouvir do que a doce e trágica história de Tristão e Isolda. Em verdade, o fascínio que cercava a população camponesa, que escutava em expectativa a dramática história desses dois seres apaixonados, não é diferente do feitiço que rodeia as canções populares, os filmes de Hollywood, as telenovelas e minisséries brasileiras

\footnotetext{
${ }^{1}$ Graduada em Comunicação Social, mestre e doutora em Sociologia pela Universidade Federal do Ceará. Professora Adjunto XII da Universidade Estadual do Ceará (UECE). Pesquisadora da área de mídia e literatura Email: manubarros@secrel.com.br.

${ }^{2}$ Graduada em Comunicação Social pela Universidade Federal do Ceará (UFC). Mestre e Doutora em Sociologia pela UFC. Professora Titular da Universidade de Fortaleza (UNIFOR). Email: eroh@unifor.br.
} 
e os romances sentimentais, que elegem o amor como tema central de seus enredos. Nesta plêiade de bens culturais, damos particular ênfase aos romances sentimentais, pois, neles, o amor é a força centrífuga, a razão de ser da construção narrativa. Esse termo genérico que engloba inumeráveis teorizações tão variadas quanto as formas de sua expressão, é o terreno privilegiado sobre o qual os romances sentimentais se assentam.

Um romance sentimental é, antes de tudo, uma obra de ficção cuja temática trata de sentimentos e paixões. São histórias de amor que concentram sua atenção na expressão dos estados emocionais e nos conflitos internos das personagens muito mais do que sobre as ações externas (SAMONÀ, 1980). Este novo gênero, surgido, na Europa, em fins do século XIX, derivado dos romances folhetins ${ }^{3}$, se coloca como um dos carros-chefe da literatura de massa ou popular. Mas, os romances sentimentais, não tratam do amor sob qualquer forma, em geral, o fazem, instituindo uma retórica do excesso.

O leitmotiv de seus enredos está centrado na construção de certa cultura dos sentimentos, enaltecida e exacerbada. Essa "extravagância emotiva" se impõe a partir de uma estrutura dramática que exibe os sentimentos desregradamente, o que exige dos seus leitores uma resposta em riso, pranto, suor, palpitação e estremecimento, no que, enfim, chamamos de emoção. Neste contexto, o ato de leitura além de pressupor entendimentos por parte dos leitores do gênero e de suas regras ou convenções (CHARTIER, 1992, ISSER, 1974), deve ser combinado com a habilidade e a vontade de se engajar emocionalmente na moral dos códigos de conduta das personagens. A própria estrutura do texto tem um papel essencial no envolvimento dos leitores. A característica básica do gênero é, nesse sentido, o convite implícito no texto à especulação sobre dilemas emocionais das personagens, que, nos romances sentimentais, se centram na busca/encontro/manutenção do amor. Este potencial de “engajamento" é representado, nas palavras de Brooks (1976) pela imaginação melodramática.

Esta imaginação melodramática, engajamento emocional ou extravagância emotiva tem suas origens históricas na Revolução Francesa (BARBEIRO, 1988). O melodrama nasce em um mundo no qual os imperativos tradicionais de verdade e ética foram postos em xeque. Um novo mundo cria a necessidade de uma nova cronologia e de uma nova moralidade. Segundo Brooks (1976), nesse mundo pós-revolucionário, a república se torna a instância por excelência da moralidade. Nesse contexto, é preciso produzir melodrama para justificar a

\footnotetext{
3. Para Meyer (1996), os romances sentimentais são derivados dos romances folhetins, em sua terceira fase. Os romances folhetins, em sua terceira fase, retratam o que Meyer chama de "dramas da vida" nos quais é mostrada a luta das personagens para a vivência do verdadeiro amor, usurpado por vilões vis e pérfidos, que trazem os mais atrozes sofrimentos aos protagonistas.
} 
incessante luta contra inimigos, vilões, subornadores da nova moralidade que devem ser expurgados e confrontados para que a virtude triunfe, tornando as novas representações legíveis e claras para todos. Podemos dizer que o melodrama é um dos modos de demonstrar, de tornar operativa a essência moral de um universo pós-revolucionário. O melodrama é, pois, uma forma cultural que se tornou popular no século XIX, especialmente entre as classes populares, e desde então tomou status de cultura inferior.

$\mathrm{Na}$ óptica da literatura erudita, no modelo melodramático, as personagens, são tomadas por suas emoções violentas, dentro das quais parece não haver lugar para a reflexão, para o distanciamento intelectual ou para a relativização. Nesse sentido, o melodrama parece ser uma forma dramática cujo enredo sentimental sacrifica caracterizações por extravagantes incidentes. Em geral, é usado em um sentido pejorativo por apresentar situações aparentemente distantes da realidade, permeadas por clichês e estereótipos e, portanto, inverossímeis. O melodrama possui, porém, uma estrutura dramática bem mais complexa do que pressupõem essas afirmações.

O modo melodramático descreve uma dramatização na qual se encontra a extravagância de representações e o intenso apelo moral. Ele parece de fato encenar uma trama hiperbólica, fazendo referência a conceitos puros e polares, luz e escuridão, salvação e danação. Ele põe suas personagens no ponto de intercessão de forças éticas primárias, conferindo a elas uma carga de significado referida à luta entre essas forças. Melodrama é, pois, segundo Heilmean (1968), um modo de concepção e expressão da realidade que dá sentido à experiência através de um campo de forças semântico, no qual esses conceitos polares podem ser percebidos.

Neste modelo melodramático, o mundo é submetido a um maniqueísmo. A polarização entre o bem e o mal trabalha para revelar sua presença e sua operação como forças reais no mundo. O conflito sugere a necessidade de reconhecer e confrontar o mal, de combatê-lo e de purgá-lo para que a ordem social apareça. O melodrama revela o imperativo dessas forças, trazendo-as à luz, impondo sua evidência. O centro do interesse melodramático reside, afirma Brooks (1976), numa moral oculta. Estamos, pois, no domínio de valores que são, ao mesmo tempo, assinalados e mascarados pela realidade.

A moral oculta não é apenas um sistema metafórico, é antes o repositório de resíduos fragmentados e dessacralizados dos mitos hieráticos. Este modelo ficcional nos lança em uma esfera na qual os mais básicos desejos e interdições se encontram e aos quais devemos ascender para dar significado ao mundo. O leitor/decodificador é, pois, colocado pela qualidade performática da narrativa, se não no domínio da realidade (a violência e o 
extremismo das reações emocionais podem não corresponder exatamente ao modo como a vida é vivida para muitas pessoas), pelo menos, no das verdades morais e éticas.

$\mathrm{Na}$ contemporaneidade, encontramos essa imaginação melodramática no teatro popular, na literatura de cordel, no cinema de lágrimas latino-americano, nas histórias de detetive, na ficção científica, na literatura infantil. Convivemos com ela nas canções populares, nas telenovelas e na literatura sentimental. Neste contexto, este trabalho objetiva realizar uma reflexão sobre as interrelações entre literatura sentimental e extravagância emotiva, a partir da análise das obras de Elinor Glyn, popular autora inglesa, cujos livros foram publicados, prioritariamente, no Brasil, entre os anos 1930 e os anos 1960, pela Coleção Biblioteca das Moças.

A Biblioteca das Moças foi uma coleção que reuniu a tradução de obras de autores franceses- em sua maioria- e ingleses, destinada às mulheres da elite brasileira entre os anos 30 e 60 do século XX, cujo foco era as histórias de amor. Tal coleção, publicada pela Companhia Editora Nacional, encontra lugar em um período caracterizado pelo crescimento não só de uma literatura nacional impressa, mas, também pela tradução em massa de livros estrangeiros, que começam a ser publicados pelas editoras brasileiras. Esta expansão de mercado editorial brasileiro se dá, não só com a ampliação do interesse pelo livro nacional, mas, principalmente, pela expansão do mercado em direção a novas faixas de leitores. Neste novo nicho editorial, as mulheres eram o público alvo.

Ao invés de buscar um autor ou um título, as moças, que começam a freqüentar as livrarias, perguntam pelos livros que vão sendo publicados nas coleções a elas destinadas. O circuito de propaganda e divulgação das editoras e livrarias e as recomendações divulgadas em jornais e revistas, por pessoas que se destacavam no universo letrado, acabam por colocar a Coleção Biblioteca das Moças, como uma opção "saudável" de leitura para as mulheres das classes médias urbanas brasileiras. Entre 1935 e 1963 - período no qual houve a publicação ininterrupta de livros dessa Coleção - M. Delly ${ }^{4}$ é a autora que alcança o maior número de obras e edições. Seus livros se caracterizaram pela idealização do amor como mediador de sentimentos nobres e estados de alma positivos, como a pureza, a caridade, a fé, a honra e a força de caráter. Mas, paralela às recomendações oficiais, uma outra autora segue M. Delly de perto, em seu sucesso editorial. Tratava-se de Elinor Glyn, polêmica e controversa autora

\footnotetext{
${ }^{4}$. Entre os anos 30 e 60 do século XX, os romances de M. Delly se tornam bastante populares no Brasil, sendo indicados para a formação das nossas moças de "família". M. Delly é o pseudônimo de dois irmãos gêmeos franceses, católicos fervorosos chamados Frederic Henri de la Rosiére (1870-1949) e Jeanne- Marie Henriette Petijean de La Rosiére (1875-1947). Estes autores tornaram-se, no Brasil, ícones de uma geração e sinônimos de romances sentimentais neste período (CUNHA, 1999, ANDRADE e SILVA, 2008).
} 
popular inglesa, cujas referências a um universo de sexo, amor e prazeres estabelecem um contraponto a M. Delly.

Elinor Glyn (1864-1943) foi uma autora britânica que inaugurou o erotismo nos romances sentimentais. Foi a responsável pela criação do termo "it", que designa, em suas obras, a primeira metáfora da literatura sentimental para atração sexual ${ }^{5}$. Em seus romances, as relações homem-mulher apareciam sempre carregadas de forte apelo emocional-sexual. Neste contexto, este trabalho se propõe, pois, a realizar uma análise estrutural e argumentativa (THOMPSON, 1995) das obras de Elinor Glyn, enfocando como as concepções de amor, paixão e erotismo ali concebidas, obedecem a uma lógica melodramática, que cremos, tornoua um grande sucesso editorial no período em destaque.

\section{Corações arrebatados de amor e paixão...}

A estrutura dos romances sentimentais possui poucas variantes. Para Alberoni (1997), nos romances cor-de-rosa ou água-com-açúcar, a heroína, assemelha-se a uma mulher comum. Se nunca é belíssima, quando bonita, guarda algum defeito, a boca grande demais ou um rosto muito anguloso. É inteligente, honesta e trabalhadora. Em geral, não é rica. Não sofre de solidão, mas, não se valoriza. Mas mesmo assim, é capaz de suscitar uma grande paixão em um homem extraordinário, privilegiado em beleza, poder e status social que é, ao mesmo tempo, fascinante, irresistível e terrivelmente distante.

Mas o improvável acontece: o homem interessa-se por ela. A mulher, ao mesmo tempo em que fica transtornada pelas mais ardentes emoções, desconfia deste homem. Não se acha capaz de provocar sentimentos verdadeiros nesta criatura inatingível. A heroína foge, mas é perseguida pelo homem que se mostra apaixonado. Está convencida que de que não é amada, trata-se de amizade ou aventura. Retrai-se. Há, portanto, um duplo mal entendido: a heroína é amada, mas, duvida de si própria e crê não ter o seu amor retribuído. As aparências confirmam este prognóstico negativo. O herói a maltrata, insulta-a, manda-a embora.

A heroína crê que esteja apaixonado por outra que é jovem, bonita, sofisticada e sensual e por esses atributos que não reconhece em si, é com esta outra, imaginária, que o eleito do seu coração vai casar. As pistas que negam o milagre do amor são muitas, mas ao final, se revelam falsas. Os obstáculos, traduzidos em dúvidas e mal-entendidos, desaparecem. O homem é sincero, e jamais esteve envolvido com qualquer mulher ao não ser a amada de seu coração. Assim, o tema central da literatura cor de rosa, segundo Alberoni, se traduz no

\footnotetext{
${ }^{5}$. Além de escritora, Elinor Glyn também foi roteirista de cinema, tendo, inclusive transposto para a tela, em 1920, “O Sheik”, filme que imortalizou Rodolfo Valentino como símbolo sexual de toda uma geração.
} 
medo feminino de não ser amada por este homem superior. O motor que o move é a emoção, é o ciúme, a paixão que faz o coração parar.

A estrutura narrativa de Elinor Glyn é muito semelhante aos romances descritos por Alberoni. As dúvidas e os ciúmes são, de fato, os obstáculos que impedem que o casal amante se reúna. Essa incerteza acontece porque a mulher crê que o homem possui qualidades tão extraordinárias que o fazem inatingível para si, pois, se credita inferior ao homem em beleza, riqueza e atributos. O tema da incerteza do amor correspondido move, assim, a narrativa dramática. Mas, esta incerteza sobre o amor recíproco se revela nas mais ardentes emoções, experienciadas pelas jovens protagonistas.

Não se dirigiu à moça em particular antes de acabar a ceia. Apesar de sua raiva, de seu desgosto, de sua cólera e mesmo de sua vergonha, desejava ela intensamente que ele lhe falasse. O único consolo que teve foi que, ao sair, enquanto ela olhava muito amavelmente o conde Varishkine, surpreendeu uma expressão de despeito no rosto de Gritzko. Assim, pensou, embora êle não a amasse realmente, podia, entretanto, sentir ciúme, e isso era o mais importante. Desta forma atormentadas pela cólera e pelo ciúme, aquelas duas criaturas atravessaram os três dias seguintes, quando suas almas eram capazes de sentimentos mais elevados e mais dignos. (GLYN, Seu único amor, 1955: 105).

Mas, na proporção em que se comunicam pessoalmente, os amantes constituem um universo simbólico próprio, distinto do entorno anônimo e impessoal. A constituição simbólico-expressiva do código amoroso o torna fortemente vinculante, já que ele só diz respeito àqueles que se amam, ao mesmo tempo em que se revela muito frágil, pois, qualquer pequeno mal-entendido pode produzir grandes tremores no subsistema íntimo. Segundo Costa (2005), na comunicação amorosa, o que conta não são os temas sobre os quais se conversa, mas a construção conjunta de uma esfera íntima, diferenciada do "mundo constituído anonimamente".

É assim, que em Glyn, a comunicação entre os amantes não se confunde com a esfera verbal-racional. Ela pode, inclusive, não existir e comumente é substituída por formas de comunicação não-discursivas, como a troca de olhares e o toque corporal capazes de desencadear diálogos que independem de qualquer tipo de mensagem objetiva. Trabalhadas nos corpos, tais emoções ocultam/revelam as perturbações inerentes aos corações apaixonados.

Pode estar certa, madrinha, de que Gritzko não sente nada por mim. Está agindo tão sòmente impulsionado pelo orgulho. Se me procura, é apenas para acrescentar mais um nome à lista de suas conquistas. Não quero prestarme a isso, Não, não quero! (GLYN, Seu único amor, 1955: 103).

Em Glyn, o amor é um estado final de uma procura que só não é alcançada quando não há coragem ou nobreza bastante para vencer os obstáculos. Mas, não se trata, aqui, do amor 
decantado pelos poetas gregos, narrado em seus mitos pelos filósofos, do amor distante dos provençais ou do amor trágico dos amantes modernos (LAZARO, 1996). Trata-se da criação de duas variantes do amor: o amor romântico, que se eleva como categoria social a partir da consolidação da burguesia como classe dirigente, no século XIX; e o amor paixão, típico da indústria cultural do século XX.

Em suas obras, encontramos com clareza a expressão mais bem articulada deste amor romântico. É um amor destinado ao casamento, amor de companheiros, ligado à responsabilidade mútua de maridos e esposas pelo cuidado da família ou da propriedade (GIDDENS, 1993). Tal amor se projeta em dois sentidos: apoia-se no outro e o idealiza, projetando um curso para o seu desenvolvimento futuro. Supõe-se, assim, que este seja não só universal, mas, também o refúgio onde resistem todos os ideais de transcendência, felicidade e solidariedade do mundo moderno.

É preciso que vivamos um para o outro, querida! Naturalmente, cumpriremos com os nossos deveres sociais; mas a nossa verdadeira vida terá lugar em Milaslaw, só para nós dois (...). Minha pátria deve ser a tua pátria. Meu corpo o teu e minha alma a tua. Amo-te mais do que tudo na terra... E serás minha, até que nos separe a morte! (GLYN, Seu único amor, 1955: 103).

No âmbito da literatura sentimental, o encontro amoroso é uma promessa de felicidade que se dará a partir do momento em que "dois corações se deixem arrebatar pelo amor". A mensagem é clara: na história milenar da humanidade só o amor permanece como garantia de felicidade. Este amor será descrito como a grande experiência de singularidade do indivíduo que se definirá pela intensidade de sua experiência amorosa (LÁZARO, 1996). Essa intensidade se estabelece a partir da interiorização do amor no indivíduo, em suas experiências de alegria e sofrimento.

Assim, o amor romântico reivindica e absorve as pessoas tornando as outras referências do entorno social pouco importantes. Para Giddens (1993), o amor romântico introduziu a ideia de uma narrativa para uma vida individual que, ao inserir o eu e o outro em uma narrativa pessoal, o desliga dos processos sociais mais amplos. Neste sentido, o amor romântico constitui a última fonte geradora das utopias de transformação e ruptura da ordem cotidiana, necessárias à reprodução simbólica e material do capitalismo. É assim que, para Illouz (1997), os amantes se veem tomados por uma energia criativa e transformadora, de modo que quem ama se sente como um revolucionário estimulado a transgredir a normalidade, vivendo com a pessoa amada experiências de amor pungentes que tentam escapar ao registro da ordem estabelecida. 
Neste sentido, em Glyn, o apelo à paixão toma o lugar central da narrativa. Nela, o amor só é legitimado pela intensidade arrebatadora, cuja expressão oferece a garantia de legitimidade da experiência amorosa. Configura-se, assim, uma nova modalidade do amor sentimental, a do desejo-à-primeira-vista. Ele ocorre simultaneamente ao amor-à-primeiravista que Giddens (1993: 51) define como "uma atitude comunicativa, uma apreensão intuitiva das qualidades do outro. É um processo de atração por alguém que pode tornar a vida de outro alguém, digamos assim, completa". Este seria o ideal da simbiose perfeita. Cada um serve como elemento fortalecedor do outro, ou seja, a mulher deseja porque ama e ama porque deseja.

A admirável conformação dos ossos daquele divino rosto, mesmo visto sob à luz de um lado só, não originava desfigurantes sombras a cair-lhe sobre a boca... Aquela mulher encheu-o de desejo de tocá-la, de apertá-la, estreitamente em seus braços, de desmanchar aqueles cabelos cor de ouro e de cobrir o seu rosto com os dourados fios. Contudo, lord Tancredo não era um homem sensual, desses que à primeira vista se dão conta dos encantos físicos das mulheres (...)...e se fosse verdade aquilo que a esposa lhe dissera? Não passaria tudo de um mero desejo? Acaso perdera o juízo e intoxicara-se simplesmente pelo desejo ante aquela singular formosura? Além disso, não havia mais nada? Seriam os homens realmente uns brutos? Chegou à conclusão de que para a sua natureza não havia amor sem o desejo, e não era possível o desejo sem amor (GLYN, Por que?, 1956: 26-115).

Assim, a mulher, em seus romances, é vista e desejada, tal como o homem também o é. O amor-paixão agora é pensado desde o primeiro momento da relação, tornando impossível sua manutenção sem que ele esteja presente (GIDDENS, 1993). Em Elinor Glyn, não basta mais ao homem casar-se com a mulher e constituir família. A masculinidade agora se enaltece na promoção do prazer da companheira.

Durante um segundo perpassou-lhe pela mente a idéia de logo à noite agarrála, tratá-la como se de fato fosse a pantera negra com que tanto se parecia, conquistá-la pela força bruta, maltratá-la se fosse preciso, e beijá-la, beijá-la até tirar-lhe a respiração! (GLYN, Por que?, 1956: 239).

Sendo assim, o prazer masculino passa a estar intimamente ligado ao feminino, bem como às glórias da conquista amorosa. Por isso, mesmo quando a mulher contrai matrimônio contra a vontade, será objetivo primário do homem, conquistá-la e forçá-la a admitir que o ama e o deseja carnalmente. Assim, a obra de Elinor Glyn apresenta uma concepção de amor que se expressa como um vínculo com o outro que não conhece desejo mais ardente que a vontade de conduzir a própria vida no corpo da pessoa amada.

Jonh Gaunt, por seu lado, analisava todas as linhas do corpo dela. Seu frio e reflexionador método de deduções dissecava-a, despia-a. (...) E teve consciência da poderosa atração que exercia, sentindo, no mesmo instante, o desejo de beijar aqueles lábios de cereja e de esmagá-los nos braços a ponto 
de não a deixar respirar... quando chegasse a ocasião... (GLYN, O It, 1940: 13-14).

A esse respeito Giddens (1993) afirma que o amor apaixonado é marcado por uma urgência que o coloca à parte das rotinas da vida cotidiana, com a qual, na verdade, ele tende a se conflitar. Condensam-se, assim, historicamente no amor em Glyn a unidade entre paixão sexual e afeição emocional, entre amor e matrimônio e a constituição de uma prole. Entretanto, este apelo sexual se dá na dimensão das emoções, relacionadas às palpitações do coração, à tremulação das mãos, à emoção que rouba o colorido da face ou a incendeia.

Em toda a sua vida sempre suave, convencional e correta, jamais havia experimentado tal emoção Pela segunda vez na vida, Tamara ficou numa palidez de morte. Até os seus lábios perderam a cor (...) Pareceu-lhe que o solo lhe fugia debaixo dos pés; os joelhos lhe tremeram violentamente. (Glyn, Seu único amor, 1955: 54- 96).

Mas, se o amor, em Glyn, aparece como uma síntese dos ideais, por um lado, do amor romântico e do outro, do amor paixão, este amor híbrido encontra lugar na ars erótica.

\section{O Drama das Emoções e o Erotismo}

Em Glyn, o erotismo adquire nuances diferentes daquelas percebidas na contemporaneidade. Se hoje, encontramos, nas bancas, a revista erótica dedicada ao público masculino, e de outro lado, a literatura erótica, destinada às mulheres, na literatura sentimental do início do século XX, erotismo, amor e paixão são três instâncias de ação humana complementares, cujos desdobramentos não se vinculam à nudez nem ao ato sexual em si. Este erotismo está ligado a uma experiência interior que, apesar de ter como princípio norteador a centralidade do corpo, estabelece um diálogo direto com as emoções (BATAILLE, 1980).

Em Glyn, este erotismo feminino é traduzido numa ansiedade pungente, baseada no medo de não ser amada pelo eleito do seu coração. $\mathrm{O}$ erotismo atinge seu ponto nesta tensão, nesta indagação contínua, sempre desiludida e sempre renascente: ele gosta de mim? $\mathrm{Me}$ deseja? Me ama? (ALBERONI, 1986). O que há de verdadeiramente erótico, no erotismo feminino, segundo Alberoni, não é o relacionamento sexual, mas o arrepio causado pela emoção, a paixão que embota os sentidos, que aperta o coração, que faz sofrer, que faz esperar e suspirar. Este exacerbamento das emoções, marca dos romances sentimentais, forma um contraponto com o processo civilizador ${ }^{6}$.

\footnotetext{
6. O século XX leva às massas urbanizadas pela industrialização os modelos e padrões de conduta, ação e sensibilidade elaborados no interior das classes burguesas. É a inclusão das massas no processo civilizador. Mas, se no decorrer deste processo civilizador, protagonizado pela burguesia, as emoções foram excluídas do palco da vida comunal e investidas de sentimentos de vergonha (ELIAS, 1995), os romances sentimentais, porta-vozes
} 
Assim, é inserida na lógica do excesso o que Glyn denomina de It. Tratava-se de um estranho magnetismo que irradiam homens e mulheres, independe da beleza física, é algo que emana da energia sexual de algumas pessoas, percebido no momento exato em que penetram no ambiente. Essa forma de tratar a atração entre dois seres de sexo oposto marca a entrada do erotismo na literatura sentimental. Franconi (1997) adverte que a intensidade da relação amorosa, o erotismo, não tem por enfoque o ato sexual em si, mas os matizes da sensualidade que presidem a intimidade entre os sexos. É esta gama de possibilidades que Glyn tenta transcrever em suas páginas.

Muito cedo, em sua carreira, chegara a conhecer as mulheres - e o que elas significavam para os homens. Era possuidor daquele indizível encanto, repassado de forte magnetismo a que apenas se pode dar o nome de "it" ou "misterioso quê" e por essa razão os gatos - e as mulheres também - sempre adivinhavam quando ele entrava em alguma sala (GLYN, O It, 1940: 06).

A matéria prima de Elinor Glyn é um amálgama dos três atributos da linguagem erótica: a animalidade, o apelo às emoções e a violência. $\mathrm{O}$ erotismo é definido por Bataille (1980) como um elemento diferenciador entre o homem e o animal. Nessa perspectiva, a gênese do erotismo está ligada à constituição dos traços definidores do homem, que se desvencilha da animalidade ao transformar a sexualidade em erotismo. Nas sociedades, de modo geral, independente do tempo e do espaço, o interdito está na gênese da conduta erótica, cuja transgressão é possível porque existem as proibições.

Ainda não sentira sensação idêntica, exceto numa de suas caçadas de leões, na África, quando ao seu acampamento chegou a nova de que um excepcional e lindo exemplar fora descoberto nas imediações, e que no dia seguinte podia ir no seu encalço. Os seus instintos esportistas pareciam despertar inteiramente (...) Quem quer que tenha observado um felino em sua jaula, e tenha notado toda uma gama de emoções - taciturna tolerância, suspeita, ressentimento, ódio e raiva, bem como contentamento e felicidade - que possa aparecer em sua órbita, sem a menor alteração na boca ou no queixo, entenderá a linguagem daquelas duas manchas de nanquim, enquanto Zara permanecia num silêncio de gelo.. (GLYN, Por que?, 1956: 27-89)

Inserido no mundo do trabalho, que se ordena pela razão convencional e para o qual destina parte da sua energia, o ser humano, ao viver a experiência interior do erotismo, sente-a como uma oposição violenta e violadora a tudo o que o cerca. Enquanto o trabalho representa o possível dentro de seus limites, a experiência interior traz a possibilidade de reversão desses limites. Nisso reside a natureza da transgressão erótica: de um lado estão as proibições ligadas

dos amores exacerbados e dos sentimentos intensos serão, cremos, uma tentativa de fuga deste controle. É, pois, neste contexto que vimos a junção entre erotismo e literatura romântica que passa a priorizar a sedução e tem como desfecho a efetivação do ato sexual. 
à ordem; de outro, a possibilidade de ultrapassar o ordinário e resgatar o que o mundo do trabalho e da razão sonegam.

Nesse momento sentiu caírem para ela todas as cadeias da civilização, todas as convenções da sociedade. Enquanto se achava às voltas com o botão do sapato, reconhecia não passar então de uma criatura primitiva que amava aquele homem singular com todo o seu coração apaixonado e que por todos os meios possíveis desejaria arrebatá-lo às demais mulheres. E teve consciência de que o desejava (GLYN, O It, 1940: 126).

Assim, o erotismo se dá, em Glyn, porque seus protagonistas são dotados da mais profunda emoção. Entrementes, tal emoção, deve ser controlada, pois, seu controle é, para o imaginário burguês, sinal de fidalguia, de dignidade e de honra. E assim, cria-se um paradoxo, quanto maior o controle das emoções, maior o "it" de seu casal amante.

Ava sempre dominava suas emoções e usara máscara na vida social. Não era como as moças inexperientes e simples da cidade em que nascera. Freqüentara a sociedade, aprendera a ocultar as feridas do coração e, quando alcançava sua memória, vivera sempre com a alma blindada de ferro e, depois, aquele quê indizível a que chamam, às vezes, orgulho dos bemnascidos, também veio em seu auxílio. Sentia igualmente, íntima perturbação, mas não a deixava transparecer; e ali estava sentada, toda fria, a estender para o fogo as mãos marfíneas, que quase apresentavam aos olhos de John Gaunt uma rósea diafaneidade (...) (Tratava-se) do "it" - esse estranho magnetismo que irradiam inconscientemente certos seres e que eles perdem quando o procuram utilizar conscientemente... O "it" de John Gaunt era infinitamente mais forte devido à sua vontade de ferro e império sobre si mesmo (GLYN, O It, 1940: 75-82).

Neste sentido, o anseio por uma relação amorosa que envolva plenamente os amantes continua sendo uma aspiração generalizada nas sociedades modernas. Assim, na modernidade tardia o amor romântico em sua simbiose com o amor paixão segue desempenhando papel central como ideal amoroso e desencadeador das emoções correspondentes. Num mundo onde um significado imanente não tem mais um chão, o exacerbamento das emoções existe, na literatura sentimental, para reassegurar que a vida pode ter significações.

De acordo com Ang (1985), a imaginação melodramática resistiu ao tempo porque provê os leitores de um sistema, de um modo de entender o mundo, mesmo quando o excesso é predominante. O melodrama tenta entender como os desejos e interdições funcionam e são postos em tensão, estabelecendo a diferença entre o certo e o errado. Ele transita entre modos, sexualidades, discursos, e os paradoxos da balança são a grande fonte de poder e fascinação.

Assim, longe de constituir uma série de clichês vazios e irreais, a representação do excesso é, como assinala Montes (1983), antes de tudo, produto de um realismo psicológico que procura pintar um retrato fiel, não de indivíduos, mas de emoções, paixões e estados morais dos seres humanos. Trata-se, como afirma Brooks (1976), do esforço de fazer do real e 
do ordinário da vida privada, interessantes, pela sua exacerbação dramática. Mas, este ordinário, da vida privada, é cingido, nos romances sentimentais, pela força extra-ordinária do amor.

No entanto, esse desejo de intensidade coexiste com mudanças importantes no padrão romântico da relação a dois. Como prática cultural, o amor está incorporado num amplo leque de produtos, objetos, locais e rituais. Assim, nas sociedades contemporâneas, em especial, na literatura sentimental, há estruturas que marcam os ideais e sentimentos amorosos, além de contextos para a vivência do amor. E estas vivências estabelecem a retórica do excesso que define, ainda hoje, a literatura sentimental do milênio que se inicia.

\section{BIBLIOGRAFIA}

1. ALBERONI, Francesco. O erotismo. Rio de Janeiro: Rocco, 1997.

2. ANG, I. Watching Dallas: soap-opera and the melodramatic imagination. London: Methuen, 1985.

3. ANDRADE, R.M.B; SILVA, E. H. Os Livros do Coração: uma análise dos romances sentimentais do século XX IN: Revista Contracampo (UFF). v.18, Rio de Janeiro, 2008.

4. BARBERO, J. M. De los medios a las mediaciones- comunicacion, cultura e hegemonía. México: Gustavo Gili, 1988.

5. BATAILLE, Georges. O erotismo: o proibido e a transgressão. Lisboa: LP\&M, 1980.

6. BROOKS, P. The melodramatic imagination. London: Yale University Press, 1976.

7. CHARTIER, Roger. Textos, impressões, leituras In: HUNT, Lynn. A nova história cultural. Rio de Janeiro: Martins Fontes, 1992.

8. COSTA, Sérgio. Amores fáceis. Novos estudos CEBRAP. No.73, São Paulo: Nov. 2005.

9. CUNHA, Maria Teresa Santos. Armadilhas da sedução - os romances de M. Delly. Belo Horizonte: Autêntica Editora, 1999.

10. ELIAS, Norbert. O Processo civilizador. Rio de Janeiro: Zahar, 1995.

11. FRANCONI, Rodolfo A. Erotismo e poder. São Paulo: Annablume, 1997.

12. GIDDENS, Anthony. A transformação da intimidade: sexualidade, amor e erotismo nas sociedades modernas. São Paulo: Editora da Universidade Estadual Paulista, 1993.

13. GLYN, Elinor. O It. São Paulo: Companhia Editora Nacional, 1940.

14. GLYN, Elinor. Por que? São Paulo: Companhia Editora Nacional, 1956.

15. GLYN, Elinor. Seu único amor. São Paulo: Companhia Editora Nacional, 1955.

16. HEILMEAN, Robert Bechotold. Tragedy and melodrama-versions of experience. Seattle and London. Washington: University of Washington Presse, 1968.

17. ILLOUZ, Eva. Consuming the romantic utopia. Berkeley: University of California Press, 1997.

18. ISER, J. The implied reader: patterns of communication. Baltimore: John Hopkins University Press, 1974.

19. LÁZARO, André. Amor: do mito ao mercado. Petrópolis:Vozes, 1996,

20. MEYER, Marlyse. Folhetim. Rio de Janeiro: Companhia das Letras, 1996.

21. MONTES, Rosangela Lúcia. O poder e a cultura: novos temas, velhas reflexões ou pode as emoções ensinar a obediência política? In: Revista Discurso, no15, FFLCH-USP, 1983.

22. SAMONÀ, Carmelo: Los códigos de la novela sentimental IN: Historia y crítica de la literatura española. Barcelona: Crítica, 1980. 
23. THOMPSON, John B. Ideologia e cultura moderna: Teoria social crítica na era dos meios de comunicação de massa. $4^{\mathrm{a}}$ ed. Petrópolis: Vozes, 1995. 